Nicolaus Copernicus University

Toruń

Tomasz Komendzinski

\title{
FALLIBILISM AND PROGRESS OF SCIENCE
}

A good deal of contemporary philosophy of science is historical in character; it has, nevertheless, an epistemological side. Questions about the epistemic status of scientific knowledge are the key to understanding of various pictures of the history of science. Three epistemological positions are relevant here: dogmatism, fallibilism, and scepticism. Historically oriented philosophy of science looks at science primarily as a process (but this does not preclude but rather presupposes some conception of how it is structured at a time). Thinking of science as a process assumes some model within which the phases of the developmental process take place. Now, it is our belief that some epistemological (background) assumptions must be made in order to make sense of the normative notion of the progress of science.

I think that controversies in the historical perspective of the philosophy of science are related to the line: philosophy of science - history of science - science and are concerned with a degree in which some conceptions of the philosophy of science are „forced" in to the boxes of the history of science. In the nonhistorical trend of the philosophy of science controversies are situated along the line: Science - structure of science - philosophy of science (methodology of science) and are concerned with a degree in which conceptions of the philosophy of science reconstructs some period of history of science ${ }^{1}$

My aim in the present paper is:

1) to offer alternative model formulations of the future of science in the historical philosophy of science;

${ }^{1}$ One needs to consider rather structure of science than some period with history of science. 
2) to elucidate relations between fallibilism, scepticism, and dogmatism;

3) to propose a model of the fallibilistic philosophy of science; and

4) to elucidate possible various versions of the progress of science in the fallibilistic model.

\section{FALLIBILISM, SCEPTICISM AND DOGMATISM}

Present fallibilism reflects alternative and dichotomical nature of the contemporary philosophy of science. Actual - future, true - putative, statical dinamic, finity - infinity, these are some alternatives in the epistemological characteristic of the philosophy of science in second period of the XX century.

Fallibilism is ,,an intermediate epistemological position less optimistic than dogmatism, but at the sometime less pessimistic than scepticism" " ${ }^{2}$. It is a line from Peirce's conception of fallibilism. What are the tenets claimed by fallibilism? What the tenets claimed by dogmatism? What are the tenets held by scepticism? We have the following picture ${ }^{3}$ :

Susan Haack says that „Peirce holds than any of our beliefs could be mistaken, that dogmatism is too optimistic and scepticism too pessimistic" 4 .

The above picture suggests contradiction between the approaches of dogmatism,

OPTIMISM

dogmatism

some of our beliefs

could not be wrong fallibilism

any ci our beliefs

could be wrong
PESSIMISM

scepticism

all of our beliefs

could be wrong

fallibilism and scepticism. I think that it is a mistaken suggestion. Althought there are contradictions between conceptions of science of dogmatism, fallibilism and scepticism they are still related to future science. Projection of that situation to actual science is unjustified.

One should notice that:

1) Dogmatism proclaims that some of our beliefs are not wrong (if related to actual science and future science), but some of our actual beliefs are not wrong, but they may be wrong (if related to future science).

2) Fallibilism proclaims that some of our beliefs are not wrong (if related to actual science), but any (but not all) of our beliefs could be wrong (if related to future science).

2 See Susan Haaek's, Descartes, Peirce and the Cognitive Community, The Mo- nist, 1982 (2), p. 171.

3 The picture from Haaek's Descartes..., p. 172.

4 Ibid., p. 172. 
3) Scepticism proclaims that some of our beliefs are wrong (if related to actual and future science), but any (or all) of our actual beliefs could be wrong (if related to future science).

Contradictions in future science results between:

- dogmatic conception of science, which tends toward positive knowledge, which is confirmed,

- fallibilistic conception of science which tends toward positive and negative knowledge, which is disconfirmed,

- sceptical conception of science, which tends toward negative knowledge.

Here is the picture which presents situation in actual science and in future science.

Contradictions in future science:

- contradictions between actual true beliefs of dogmatism, which are true also in future science and actual beliefs of fallibilism, which may be wrong in future science (are potentially wrong);

- contradictions between actual wrong beliefs of scepticism, which are wrong also in future science and actually wrong beliefs of fallibilism, which may be true in future science (are potentially true);

- contradictions between future true beliefs of dogmatism in future science (all beliefs are true) and future wrong beliefs of scepticism in future science (all beliefs are wrong);

- contradictions between actual wrong beliefs of dogmatism, which are rejected from future science and actual wrong beliefs of fallibilism, which are in future science as negative knowledge.

In effect one needs to say that:

- there are not contradictions between dogmatism, fallibilism and scepticism in actual science,

- controversies between dogmatism, fallibilism and scepticism are relations between two periods in history of science and are stated in future science (second period in relation), and

- elements differing dogmatism, fallibilism and scepticism are of conceptual nature: aim of science, growth of science and progress of science.

I think that for the historical trend of the philosophy of science what is fundamental is not a problem of the status of actual or future science, but relation between first and second period in history of science - because the importance of concept of the growth and progress of science for considerations in historical philosophy of science. The crucial question is „How does science growth and progress? I think, that growth of science is the sequence of periods of the history of science. One needs to emphasize, that growth of science takes positive knowledge (which is 
confirmed) and negative knowledge (which is disconfirmed) into account. Progress of science may be considered as relating to:

- the future of science (expectation of the future states of scientific knowledge),

- relation between additional periods of the growth of science taking only positive knowledge into account (also negative knowledge - in historical analysis - which was confirmed in prior considered period of the growth of science which is actual negative knowledge, but was positive knowledge in prior period of the growth of science).

We have following relations between elements of the historical philosophy of science in the perspective on the future of science:

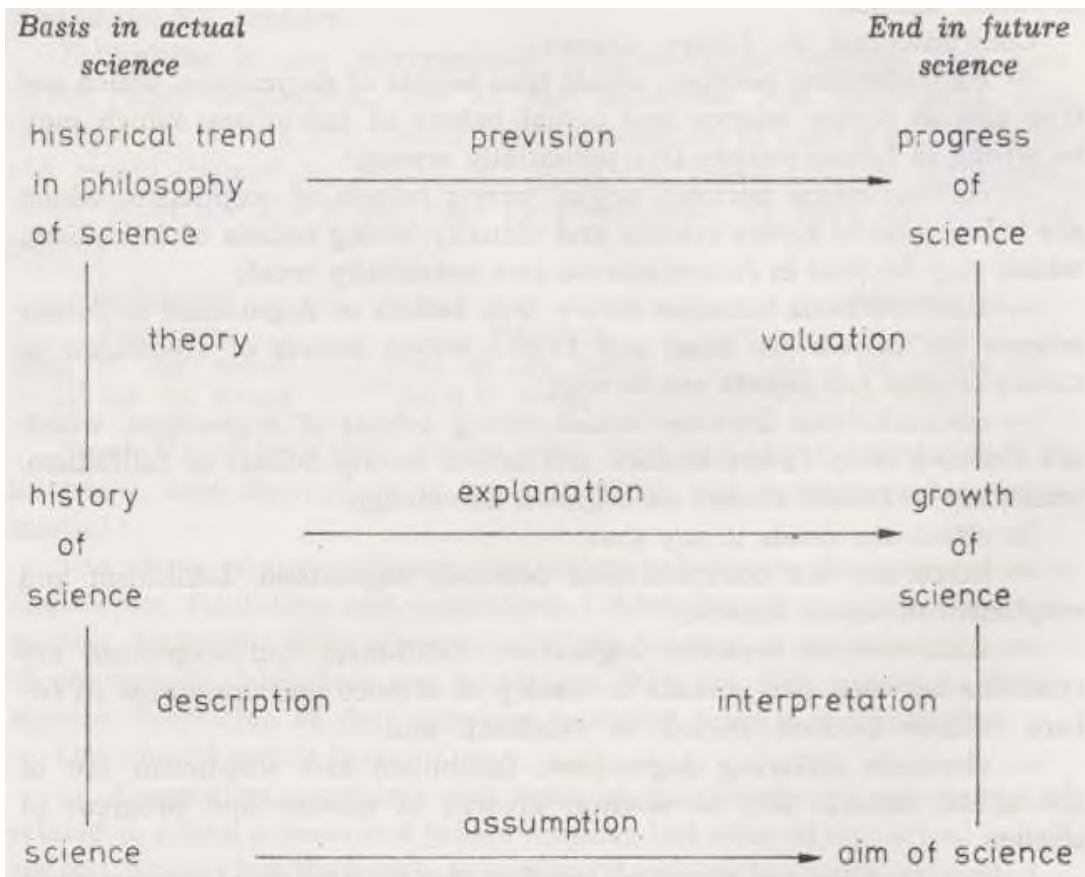

This picture represent a model situation. Philosophy of science is here placed above history of science, and that suggests a separation between philosophy of science and history of science. Practically the history of science and the growth of science level is of frequent occurrence in philosophy of science and progress of science level. I am conscious of this mediation (history of science - growth of science and philosophy of science - progress of science) and model situation. Because of that 
progress of science will be understood as the growth of science, which will be enriched by valuation with teoretical perspective some conception of the philosophy of science. The concept of the future science or future state of the scientific knowledge is directly related to the state of knowledge, which is received as result of prevision on the basis of the actual science. I tm not interested in prevision of future science, but I should like to consider question of the growth of science and relations between periods of this growth. Relation between actual science and future science will be considered as model situation for relation between two periods $\mathrm{cf}$ the growth of science in general.

Nicholas Rescher ${ }^{5}$ considers five conceptions of the future of science „They are distinguished by the way in which the choices built into the following scheme are resolved:

The prospect of ongoing scientific discovery is „limited/unlimited”. In the former case of elimitation, the limits of innovation will be eventually ,finally attained/asymptotically approached" and these limits are due to the finitude and limited complexity of „,nature/man”. Five alternative themes arise through the variation of the factors at issue here ${ }^{6}$.

These five conception of the future of science are:

1) Model of Nature Exhaustion (Ultimate Completion),

2) Model of Nature Saturation (Asymptotic Completion),

3) Model of Capacity Exhaustion,

4) Model of Capacity Saturation (Asymptotic Incapacitation),

5) Model of Unlimited Horizons (Potentially Unending Progress).

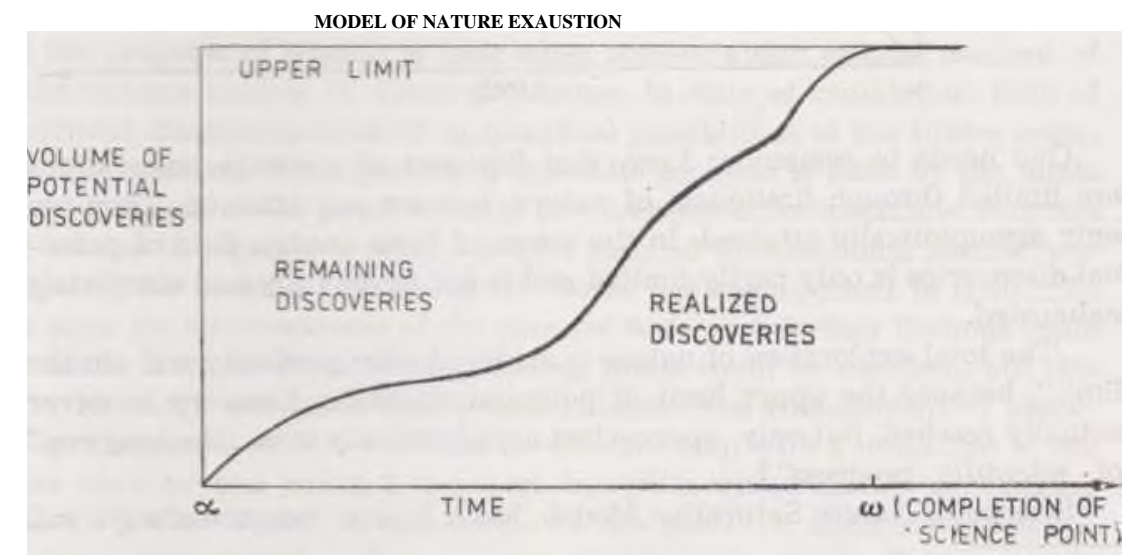

${ }^{5}$ N. Rescher, Scientific Progress, Blackwell, Oxford 1978. ${ }^{6}$ Ibid., p. 7.

Horizons of scientific innovation are limited through finiteness of nature, but in the end horizons are attained. This model is also called Ultimate Completion Model. Science has here a finite history, which is marked by two moments: a) start and some conditions and 2) ultimate point when ,,»all returns are in « because nothing of really fundamental importance remains to be discovered" ${ }^{10}$. Progress of science is here considered in terms of discovery exhaustion. We have here a case of geographic exploration, where aims of

${ }^{10}$ Ibid., p. 8 
science is attained when ,all that was once terra incognita is charted. The stock of potential scientific discoveries that reveal the „secrets of nature" is like the apples on a tree, all of which eventually get picked off, or like a vein of ore that eventually becomes exhausted" "11. In Nature Exhaustion Model is considered ultimate exhaustion of the manifold of unrealized cognitive possibilities. Aim of science is attained, when science „has no future” as an innovative enterprise.

\section{MODEL OF NATURE SATURATION (ASYMPTOTIC COMPLETION)}

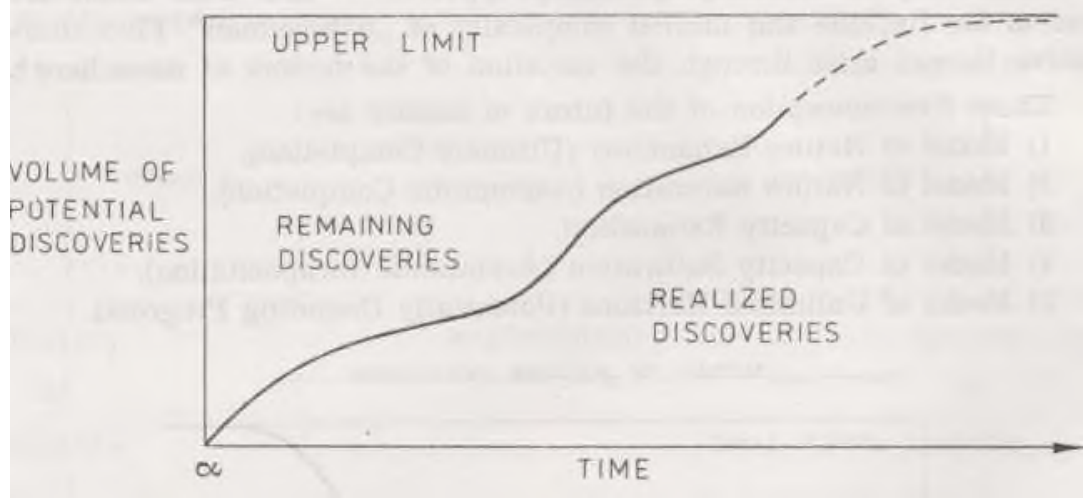

One needs to remember here, that horizons of scientific innovations are limited through limiteness of nature, but are not attained. They are only asymptotically attained. In the views of these models field of potential discoveries is only partly limited and is not never fully and completely exhausted.

„The total exploration of nature is achieved only gradually and ,in the limit”, because the upper limit of potential scientific discovery in never actually reached, but only approached asymptotically over "the long run" of scientific progress" 12 .

Science in Nature Saturation Model ,has a future” because always will

be worthwhile discoveries to be made. Appearance of news discoveries not altering essentially actual understanding of nature what is related to increase of precision in world view and making adjustments and refinements. All it turns only to marginal adjustments in our world-picture. „Scientific progress does not ever quite reach a situation, that is completed, final, and statically unchanging because the domain of potential discovery has been completely exhausted - rather, it moves toward this position by way asymptotic approximation to a finally adequate picture of the world" ${ }^{13}$.

MODEL OF CAPACITY EXHAUSTION (IMPASSABLE BARRIER)

\footnotetext{
${ }^{11}$ Ibid., p. 8.

${ }^{12}$ Ibid., p. 11.

${ }^{13}$ Ibid., pp. $11-12 .{ }^{11}$ Ibid.,

p. 48 .
} 


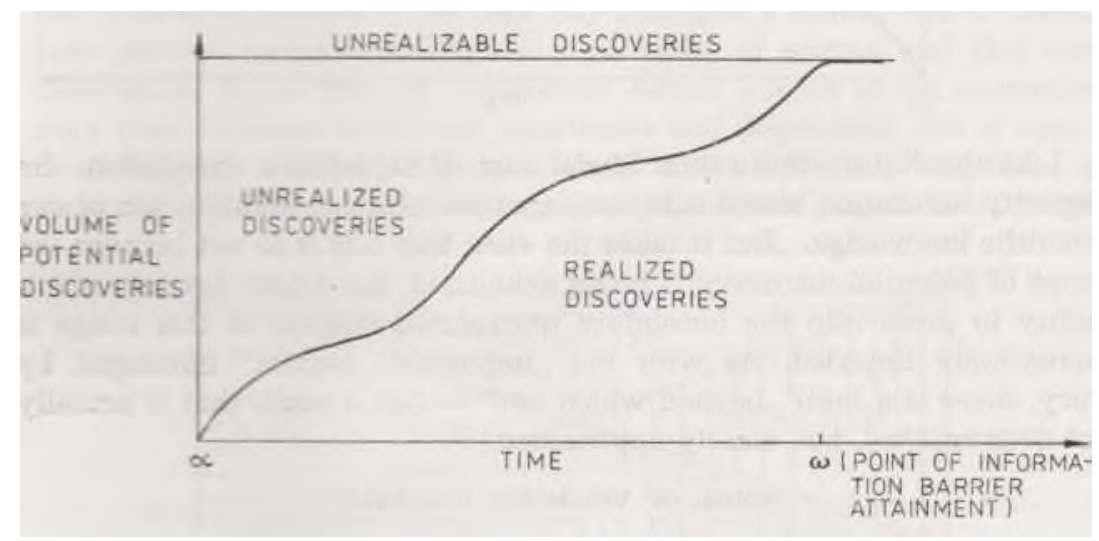

In Capacity Exhaustion Model we consider a question of completion of the progress of science in case when science attain critical moment of informations barrier. In views of Rescher, in spite of completion, field of potential discoveries consists in teoretical possibilities of the future science. The question of completion of scientific progress is risen by the limits and limitation of the possibilities in procurement of informations. Progress of science is impeded because we have reached informational barrier: our capacity for obtaing date about the world has been pushed to limit. „To be sure, the circumstances of the case are such, that further findings could be made if these information-gathering limits could be removed, but this is a visionary and unrealizable circumstance. The enlargement of knowledge in natural science comes to an ultimate stop with a limitation of nec plus ultra beyond which lies a terra incognita whose secrets our meager powers are too feeble to penetrate. We can push the scientific enterprise only „up to a point" - it is not our privilege to reach the final truth" ${ }^{\mathrm{n}}$. 


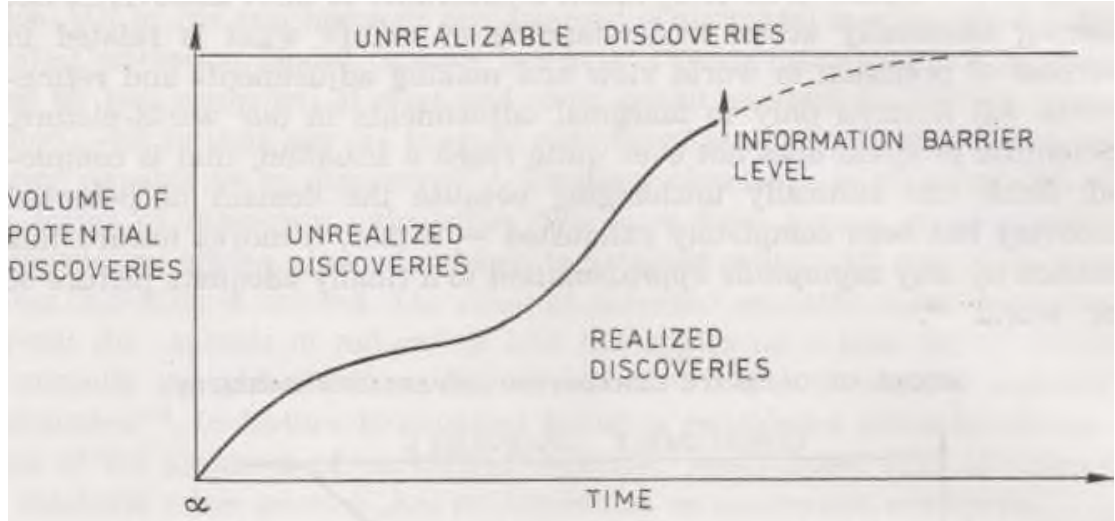

Like the Nature Saturation Model case of asymptotic completion, the Capacity Saturation Model case envisages the ultimate stabilization of our scientific knowledge. „But it takes the view that this is so not because the range of potential discovery is being exhausted, but rather because man's ability to press into the heretofore unexplored regions of this range is increasingly impeded. As with the, impassable barrier” envisaged by Bury, there is a limit „beyond which not" — but a limit, that is actually not ever reached, but merely approached" ${ }^{14}$.

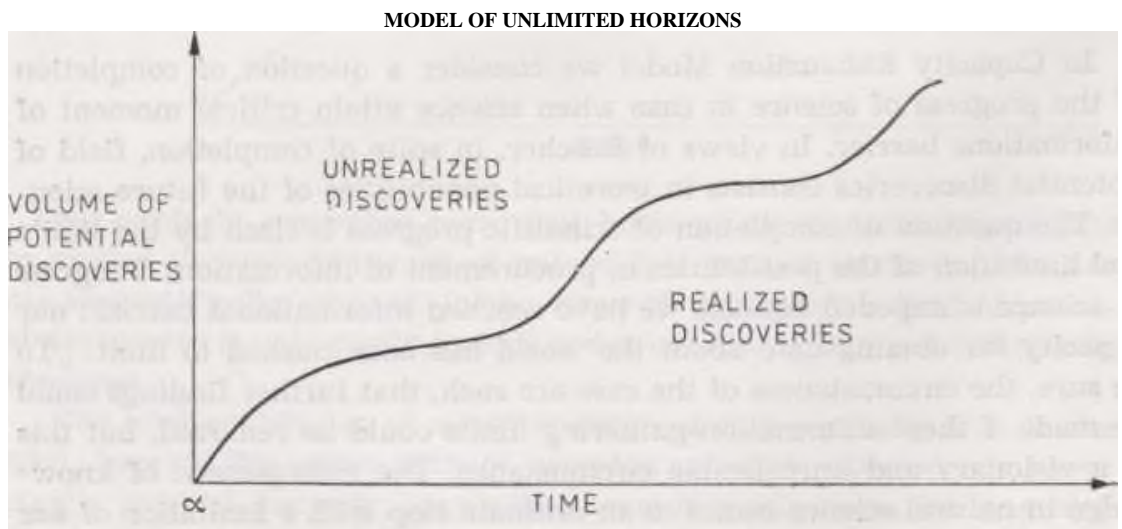

In Unlimited Horizons Model are not limits of the field of scientific progress and limits of the expansion of knowledge imposed by the limitations of man. „There is little doubt, that this is the traditional view held -

${ }_{50}^{14}$ bid., p. 13. 
or at any rate supported - by many of the greatest natural scientists from Newton to our own day. [...] To be sure, neither of these statements says flatly that the pool of unrealized discoveries is literally infinite, a thesis which - as we shall see also finds its share of advocates" ${ }^{153}$.

\section{FALLIBILISM, SCEPTICISM, DOGMATISM AND PROGRESS OF SCIENCE}

In the first part of my paper I was trying to show that in perspective of actual science have not controversy between fallibilism, scepticism and dogmatism (as conceptions from historical philosophy of science). Controversies that do appear are only related to a future science. Aim, progress and growth of science it are here kay-concepts. I should like to consider here general model of fallibilistic philosophy of science and five model conceptions of the progress of science. Actual science is not contradicto- nary level between fallibilism, scepticism and dogmatism, but is open to possibility of different interpretations from fallibilist, sceptical, and dogmatic points of view. Model situation in actual science is as follows:

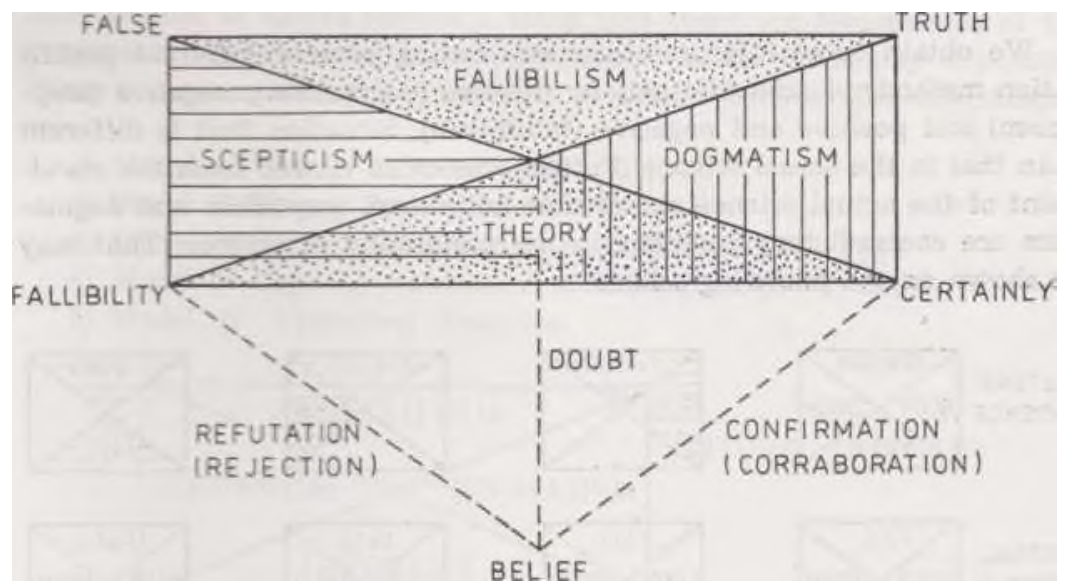

One needs to start from belief, which:

- through confirmation obtains certainty what ensure unattainable of truth,

- through refutation point to fallibility and lead to falsehood and

- through doubt one opens the way to truth or way to falsehood. Theory

represents here our first and elementary knowledge, which we hold always. On the basis of this knowledge belief is confirmed, refuted

\footnotetext{
${ }^{13}$ Ibid., p. 14.
} 
or left as non-certain, but also non-fallible. On the basis of elementary knowledge may to commits followings interpretations: fallibilistic, sceptical and dogmatistic. On present it scheme:

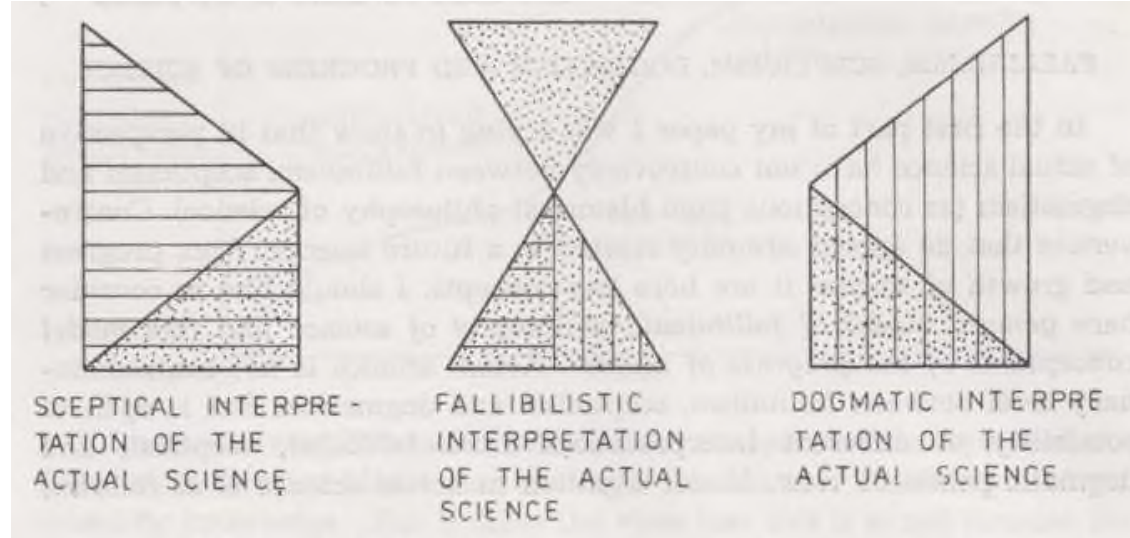

We obtain three interpretations concerning present different justification methods of scientific beliefs: positive (dogmatism), negative (scepticism) and positive and negative (fallibilism). Situation that is different than that in the actual science. Future science as viewed from the standpoint of the actual science shows that fallibilism, scepticism and dogmatism are contradictory positions in the philosophy of science. That may be shown on the following scheme:

One may perhaps notice, that are contradictory related here only to a part of
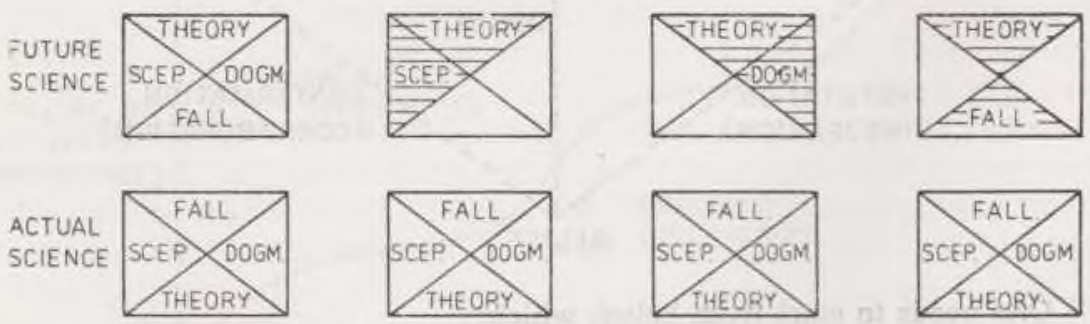

future scientific knowledge. The field representing part of knowledge on the basis of which we have not reached agreement whether has (will be to have) nature of another one mistake, knowledge, which is doomed to doubt, whether certain knowledge.

Now we shall depict a general model of fallibilistic philosophy of 
science on basis relation between actual science and future science with place and role of general concepts in science. It is picture of that relation in fallibilistic philosophy of science.

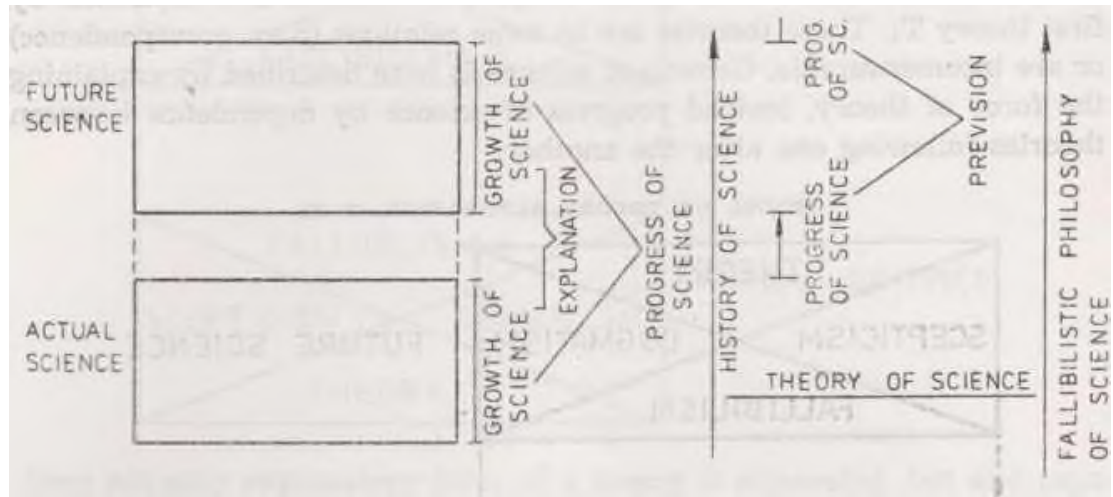

On basis considerations from that chapter and results of considerations related to future science I think that there are five models of the progress of science in fallibilistic conception of the philosophy of science. There are some analogies to models of future science. The five models are:

1) Model of Theory Exhaustion ( $\mathrm{Ti}-\mathrm{T} 2)$,

2) Model of Theory Saturation $(\mathrm{T}-\mathrm{F})$,

3) Model of Capacity Exhaustion of Fallibilism ( $\mathrm{Fj}-\mathrm{F} 2)$,

4) Model of Capacity Saturation of Fallibilism $(\mathrm{F}-\mathrm{T})$ and

5) Model of Unlimited Progress.

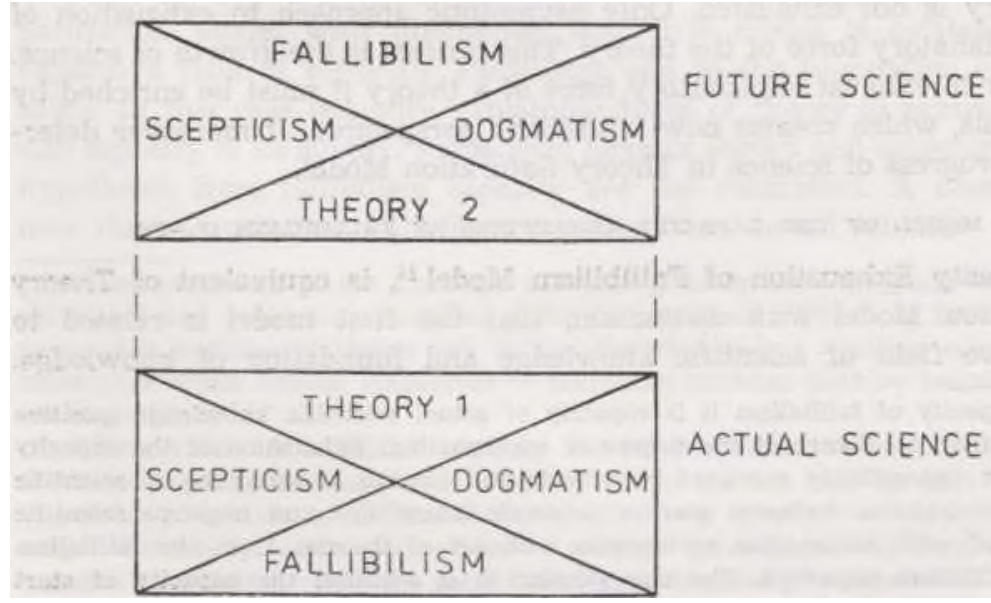

In Theory Exhaustion Model theory is characterized in terms of explanatory force and its exhaustion. If explanatory force of the theory $T_{1}$ in the field of actual 
science is exhausted the need for a new theory $T_{2}$ arises, which would be able to explain what was not explained by first theory $\mathrm{T}$. These theories are in some relations (p.ex. corespondence) or are incomensurable. Growth of science is here described by explaining the force of theory, instead progress of science by dependence between theories following one after the another.

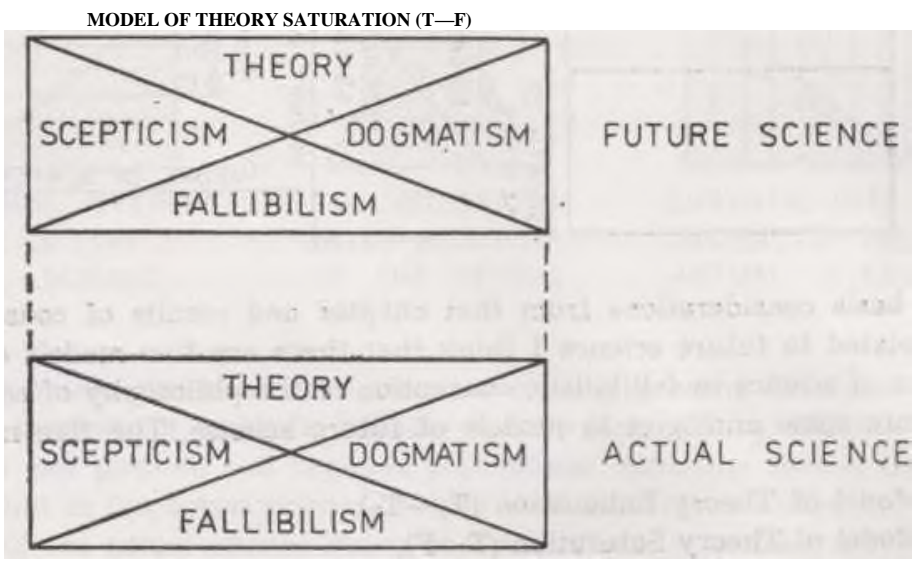

In the Theory Saturation Model theory is also characterized in terms akin to concept of explanatory force and its exhaustion. Compared with Theory Exhaustion Model in Theory Saturation Model explanatory force of theory is not exhausted. Only asymptotic approach to exhaustion of the explanatory force of the theory. This process is the growth of science. In order to exhaust explanatory force of a theory it must be enriched by hipothesis, which creates new fallibilistic perspective. It moreover determines progress of science in Theory Saturation Model.

MODEL OF THE CAPACITY EXHAUSTION OF FALLIBILISM (F-F2)

Capacity Exhaustion of Fallibilism Model ${ }^{14}$, is equivalent of Theory Exhaustion Model with distinction, that the first model is related to expansive field of scientific knowledge and foundation of knowledge.

${ }^{14}$ Capacity of fallibilism it is capacity of actual scientific knowledge (positive and negative) to change of the degree of confirmation. Exhaustion of the capacity determine impassibility move of hypothesis and change of structure of scientific knowledge (relation between positive scientific knowledge and negative scientific knowledge) with assumption agreements with set of theories from the fallibilism (from fallibilism capacity). The one solution it is addition the capacity of start 


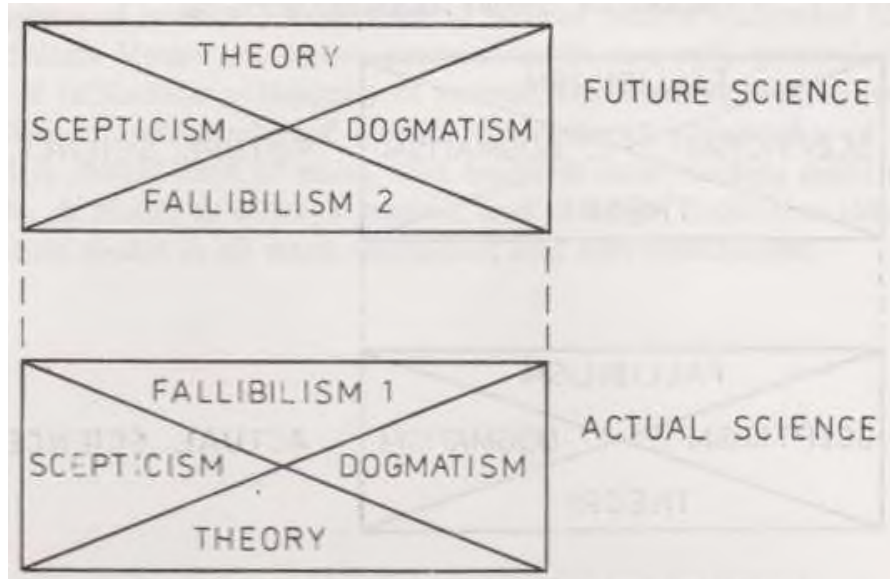

Here not only explanatory force of a theory is exhausted, but also capacity of its supply. A necessity of appealing to a new theory arises, but theory is founded on basis new hypothesis, which are not founded on the basis of hipotetical capacity of fallibilism $F_{1}$ and theory $T_{1}$. With new theory $T_{2}$ is founded new capacity making of hypothesis-capacity of fallibilism $\mathrm{F}_{2}$.

Exhaustion of capacity Fallibilism $F_{1}$ represent growth of science, relation between fallibilism capacity $F_{1}$ and fallibilism capacity $F_{2}$ determine progress of science in that model.

MODEL OF THE CAPACITY SATURATION OF FALLIBILISM (F-T)

Capacity Saturation of Fallibilism Mode ${ }^{16}$ is equivalent of Theory Saturation Model with distinction that first model is related to the expansive field of scientific knowledge and to the foundation of knowledge. In this case not only explaining force of theory is saturated, but also capacity of its supply. Explaining force of theory and capacity making hypothesis from fallibilism capacity are not exhausted. A necessity of new theory appeal to fallibilism capacity from actual science.

fallibilism or change of the structure of scientific knowledge but going beyond the agreement and coherence conditions. Difference between addition of fallibilism capacity and addition of theory lies in the fact that theory contains only positive knowledge, while holistic conception of fallibilism contains positive knowledge and also negative.

${ }^{16}$ Conception of fallibilism capacity see 14 . Difference between saturation of fallibilism capacity and saturation of theory lies in the fact that the first determine impossibility exhaustion of fallibilism capacity in a structure of scientific knowledge (structure of science is related to relation between positive knowledge and negative knowledge), while the second determine impossibility exhaustion of theory 

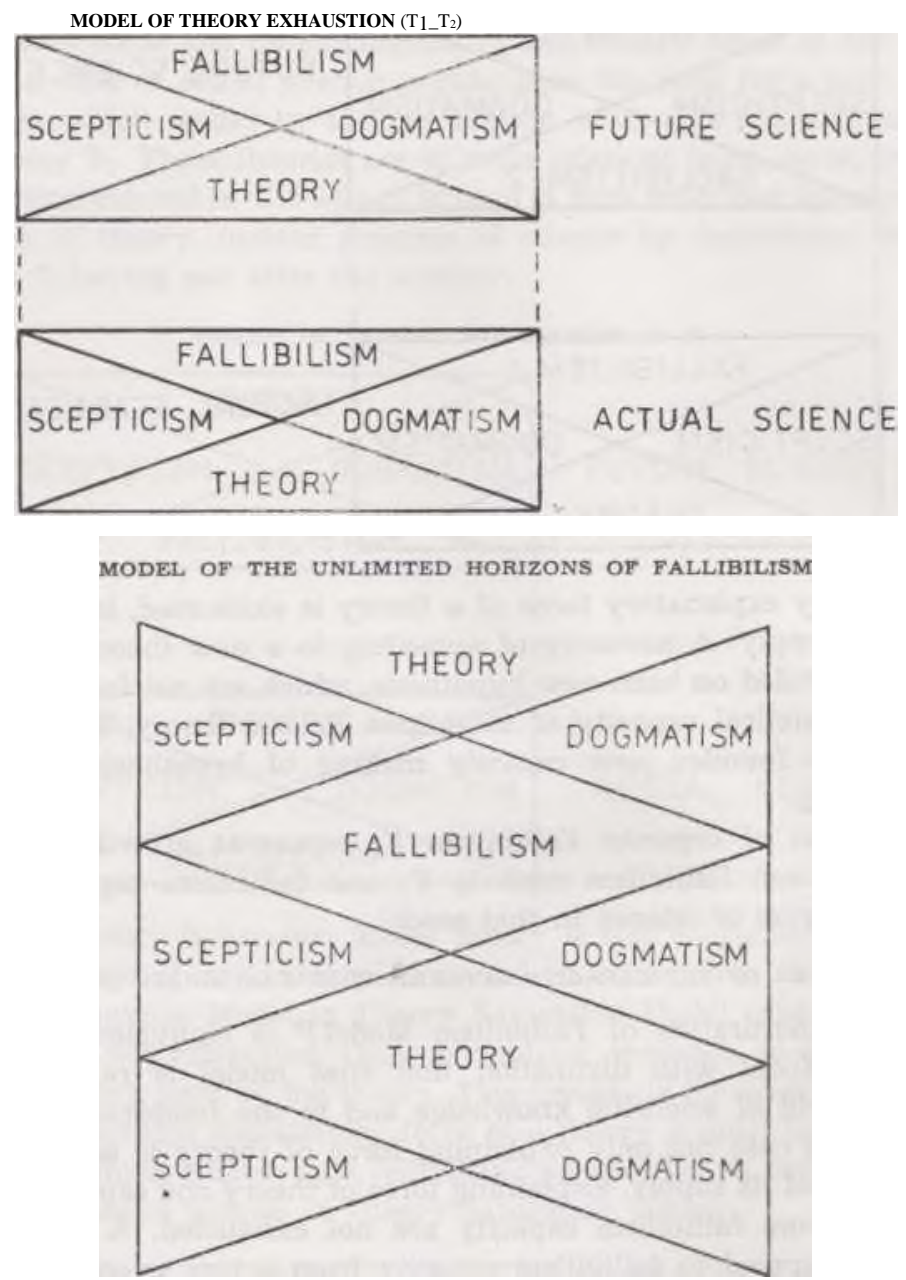

In Unlimited Horizons of Fallibilism Model unlimited horizons have fallibilistic capacity of creating new theories and producting new hypothesis. In that model there exist a possibility of the growth of science

(exhaustion of the explanatory force of positive scientific knowledge, which is represented through the theory). Addition of fallibilism capacity (new hypothesis) through change of the structure of scientific knowledge (ex. new theory), but not going beyond agreement and coherence conditions, it is a solution in case of the saturation of fallibilism capacity. 
and progress of science. Revolutions of science within Unlimited Horizons of Fallibilism Model are rather impossible. Its are only general considerations of fallibilistic philosophy of science. On needs now detail analysis.

Student of philosophy of science (in historicl philosophy of science especially) should have in mind, that model is only starting point of a set of views. A Model is allways general and „forced” from one side. From second side model is all ways redundant and also insufficient. 